\title{
The personalization of e-learning systems with the contrast of strategic knowledge and learner's learning preferences: an investigatory analysis
}

\author{
Alan Mustafa \\ Department of Information Science, The American University of Kurdistan, \\ Duhok, Iraq
}

\begin{abstract}
In this study, reasons for proving the relevancy of personalisation of e-learning systems to act as a knowledge management system in which tacit to tacit type of knowledge (socialisation) can be delivered, are being provided. Nonaka's knowledge conversion model is being used as the basis of the investigation. The relationship between 'the strategic knowledge conversion model' drawn from the 'identifying list of strategies' and 'an individual's decision-making method' has been investigated in relation to knowledge transferring systems and individual's learning styles. The outcome of the qualitative as well as quantitative investigation defines a set of frameworks in which different types of e-learning systems utilizing different learning philosophies and learners learning preferences to support the learner's learning curve.
\end{abstract}

Keywords E-learning systems, Knowledge management systems, Personalisation, Learning preferences, Tacit knowledge, Strategic knowledge management

Paper type Research paper

\section{Introduction}

Knowledge and knowledge management have always been at the heart of any advancements in the history of mankind. Teaching and tutoring were kind of tools used to transfer

(C) Alan Mustafa. Published in Applied Computing and Informatics. Published by Emerald Publishing Limited. This article is published under the Creative Commons Attribution (CC BY 4.0) license. Anyone may reproduce, distribute, translate and create derivative works of this article (for both commercial and non-commercial purposes), subject to full attribution to the original publication and authors. The full terms of this license may be seen at http://creativecommons.org/licences/by/4.0/legalcode

The author would like to thank Dr. Heja Badirkhan Sindi from The University of Kurdistan - Hawler for introducing the concept of knowledge management and how types of knowledge support the data flow and decision making process in organizations, and Prof. Abdulnasser Hatemi-J from UAE University for his invaluable support on mentoring the production of this paper.

Conflict of interest: The author confirms no conflict of interest at the time of preparation of this manuscript.

Publishers note: The publisher wishes to inform readers that the article "The personalization of elearning systems with the contrast of strategic knowledge and learner's learning preferences: An investigatory analysis" was originally published by the previous publisher of Applied Computing and Informatics and the pagination of this article has been subsequently changed. There has been no change to the content of the article. This change was necessary for the journal to transition from the previous publisher to the new one. The publisher sincerely apologises for any inconvenience caused. To access and cite this article, please use Mustafa, A. (2021), "The personalization of e-learning systems with the contrast of strategic knowledge and learner's learning preferences: An investigatory analysis", Applied Computing and Informatics. Vol. 17 No. 1, pp. 153-167. The original publication date for this paper was 17/08/2018.

Personalizing of e-learning systems 
$\mathrm{ACI}$

17,1

154

knowledge, in different forms, from a mind to another mind for the purpose of continuation of life. On its evolution path, different tools have been developed to preserve its existence despite having flexibility to be shaped into different forms. Instructional design with the support of contemporary and accessible technology has not been far from these evolution. Hence this research aims as addressing two major questions and they are: i) can a chain of knowledge conversion be used to devise a strategy where it can replace the process of tacit knowledge in which the current traditional face-to-face classroom or even in a business environment [1] being used?, and ii) what is the role of a learner's learning style in this new medium of transferring knowledge?

This paper argues that it is possible to model an instructional system based on the type of delivered-knowledge where it can support a learner-centred learning environment mostly known as personalised e-learning environment. Furthermore, the same approach can be used to investigate new models for devising new strategies on adaptable and adaptive e-learning systems. Hence, Knowledge management is the key to formulate such a strategy which requires a better understanding of its definition.

Knowledge comes with the making sense of existing collection of information in the form of understanding its purpose, its applications, and the process of creating new information. The pattern in which information is created, processed, stored and re-created again, makes the knowledge about "something" [2-4]. Knowledge is the fact or condition of knowing "about" or understanding existing fact; and knowing "how to" or the "process" of creating a new fact $[5,6]$. Knowledge is the building block of wisdom which includes data, information and the process of converting data into information. Knowledge is the raw facts data formed into information with guided actions based upon insight and experience [7]. Hence, knowledge like any other entities would require management to be applied in day to day life. It requires creating an environment in which the information could be passed along to the right person, at the right time, and in a suitable format with insights and experiences. A set of processes that creates, captures, stores, maintains and disseminates a firm's knowledge [8]. As Nonaka [2,3,9] originally defined "knowledge management" and its applications in organisations, as "a mechanism that creates new techniques, technologies, systems and rewards for getting employees to share what they know and to make better use of accumulated workplace and enterprise knowledge. In that way, employees of a company are leveraging knowledge as they do their jobs; hence, the organisational structure for managing those components is defined as the knowledge management system."

The primary objective of the knowledge management lays on the understanding of different types of knowledge which have different characteristics. In other words, by comparing the body of knowledge to a building structure, it has a process which requires an organisation. In that respect, to understand and learn about its components and finding ways to improve its efficiency, knowledge management opens up a roadmap for this purpose. Although, the cloud of the body of knowledge has its own organisational structure, by understanding its types, our awareness of its characteristics could be further expanded. As such its organisational structure could perform more efficiently and be the source of its own further development. Changes in the categorisation of knowledge have been continuously shaping the process of creating different methods of interaction. The development of these new forms of knowledge categorisation has acted as the focal point of epistemology [10-14].

Core factors of these differences are knowing-how and knowing-about. Basically, knowinghow is known as tacit knowledge, which is something that can't be articulated. The knowledge that can easily be expressed and articulated such as factual knowledge is known as explicit knowledge (knowing-about). There are two other types of knowledge which are concerns of this research. These are Implicit Knowledge and Strategic Knowledge. If knowledge has not been articulated but can be, it is called "implicit knowledge". Strategic knowledge is about "know-when" and "know-why" [10,14]. 
Nickols [15] a cognitive psychologist has proposed a view on the categorisation of strategic knowledge by counting it as a subset of other types of knowledge. On the contrary, the view of considering an individual's decision-making style as a factor in defining implicit knowledge would give the right to this type of knowledge to be a separate category in itself. This is a major key factor in the evolving process of personalisation of e-learning systems, which will be debated here.

As mentioned earlier, Nickols [15] proposed that "Strategic Knowledge" should be counted as a subset of declarative knowledge (Figure 1), its definition (know-how and knowwhy) would permit the strategic knowledge to be classified into a separate category based on its description (know-how and know-why) and not on how-to views. This separation of a type of knowledge known as "Strategic Knowledge" would prepare a groundwork towards the involvement of individual's-decision-making-style into the categorisation of knowledge. The involvement of individual's learning style with the process of (i) drawing the boundary between tacit and implicit knowledge and then (ii) converting implicit knowledge into explicit knowledge would be a strategic approach towards manipulating this type of knowledge through an information system. These concepts and processes will be explained further in the following sections.

\subsection{Knowledge management and knowledge conversion}

Cognitivist researcher Nonaka [16] proposed four different types of knowledge conversion processes: a) Socialisation, b) Externalization, c) Combination, and d) Internalization processes. These knowledge processes are needed to be able to employ a suitable format of tacit or explicit types of knowledge, so the newly formed converted knowledge is capable of flowing through a different medium (type) of knowledge.

The process of Socialisation is meant to be used to transfer the tacit knowledge as complete as possible to lessen the error involved in the process through the transferringmedium. Researchers have confirmed that it is not an error-free process to transfer tacit knowledge through a knowledge management system (KMS) $[3,17,18]$. This approach towards knowledge transferring puts any type of knowledge management information system (KMIS) into a part-solution-provider where the system would be able to deliver the knowledge in purpose with the support of a knowledge-transfer application on the base of knowledge conversion mechanism (Nonaka's spiral of knowledge creation) [19]. As such, a knowledge management system attempts to compensate for the error involved in the process of tacit-to-tacit knowledge transfer (in the form of learning) by taking a type of knowledge through a series of spiral cycles (Figure 2) known as knowledge conversion [3].

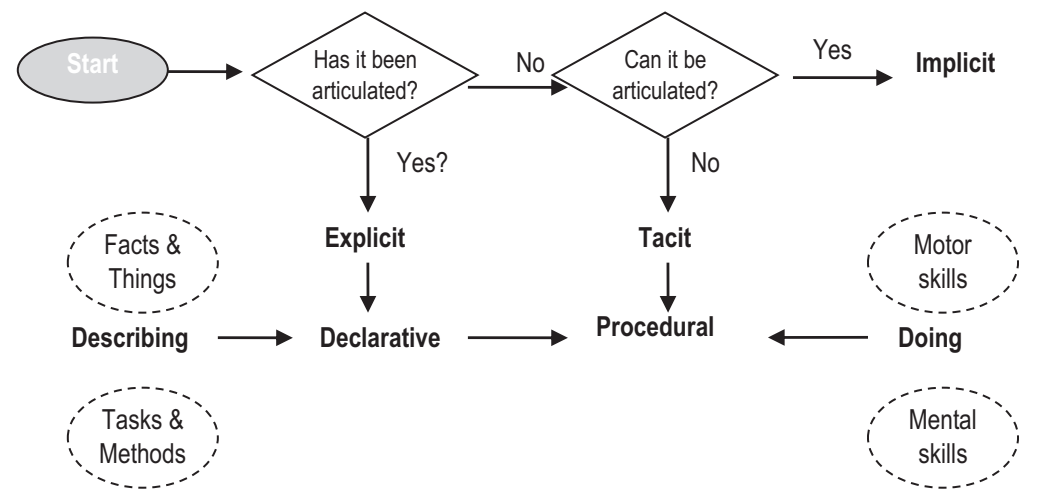

Personalizing of e-learning systems
Figure 1. A framework for thinking About the

Knowledge in

Knowledge

Management. Adapted from [15]. 
$\mathrm{ACI}$

17,1

156

Based on the spiral model of knowledge conversion proposed by Nonaka and Takeuchi [3], Figure 2, there is an indication of a solution to the issue of error compensation while knowledge of type tacit-tacit transfers. As presented on the diagram (Figure 2) (a) in a social mode the tacit-to-tacit conversion process can be demonstrated in the form of sharing ideas, presenting technical skills in a team-based activity and discussions based on a mental model through interaction between class members or a group going through a brainstorming session; (b) Externalisation mode is a form of tacit to explicit knowledge conversion which occurs when explicit knowledge is made of tacit knowledge in the form of descriptions, comparisons, hypotheses and models. As Nonaka and Takeuchi, [3] have clearly defined the tacit to explicit knowledge conversion process as an attempt to conceptualise images and then their expression in a language, wherein this form of knowledge conversion, information is mainly used to compile different analogies and metaphors for the creation of new knowledge; (c) Combination type of knowledge conversion is the outcome of combining or elaborating existing documentation in any session or class to produce new knowledge and it is known as the process of explicit to explicit knowledge conversion. The outcome of activities of any learning environment aims at combination form of knowledge conversion [20]. (d) Internalization mode defines [3] the mode as the process of conversion of explicit to tacit type of knowledge. The process of sharing information will be in the form of converting explicit knowledge into tacit actions and could be categorised as another form of learning by doing.

Alkhaldi and Olaimat [21] have indicated that the main point behind knowledge conversion within a learning environment is that the conversion does not happen within the individual teacher's mind or the learner's but between both individuals involved within that learning environment using any medium of learning. The process of knowledge conversion from one type to another and between tacit to explicit forms would indicate the process of continuous learning. In another word, the knowledge conversion requires interaction between both tacit and explicit knowledge, and between individuals and groups involved in the learning environment.

To conclude, different modes of the knowledge conversion process require four modes of interaction between tacit and explicit knowledge, as such, it starts from socialization then to externalisation, to combination, to internalization, then again to socialization and so on [22]. At each stage of conversion, different kinds of knowledge are being created, over and over again. All the way through current discussion, while the stages of the creation of different forms of knowledge were explored, the main focus of all those distinctions was about the conversion of tacit and explicit knowledge. It should be noted that the cycle or process of SECI model (Socialisation, Externalisation, Combination and Internalisation) is a constructivist approach towards knowledge conversion [23]. Following section discusses the relationship

Figure 2.

Knowledge conversion. Source: Adapted from [3].

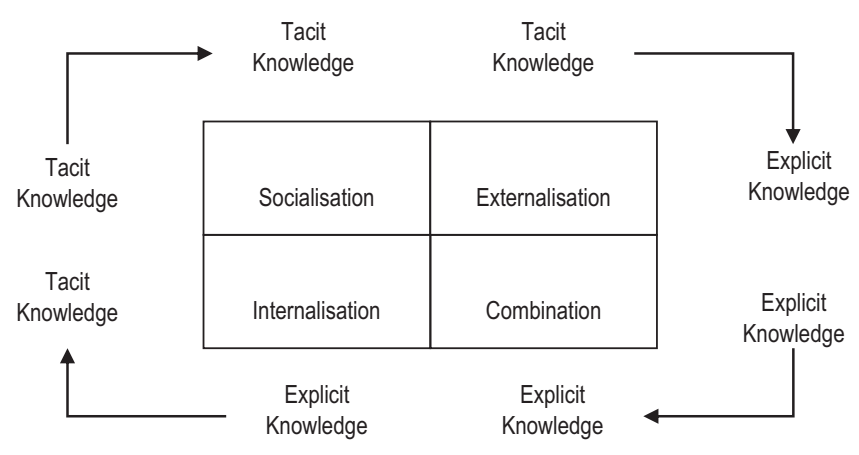


between types of knowledge and the process of knowledge conversion (SECI process) to the teacher- or learner-centred e-learning systems.

\subsection{Exploring the delivery of tacit knowledge by means of Teacher-and/or Learner-Centred systems}

The diagram in Figure 2 (Knowledge conversion) [3,16] shows the main difference between (i) teaching systems with face-to-face sessions in traditional classes and (ii) a learning system in its non-tacit delivery form of knowledge. This model supports (confirms) the necessity of having the method of spiral cycles using a learning system for this purpose (tacit-to-tacit knowledge delivery); by taking the concept through the following process:

The main purpose of teaching in a class is to deliver the tacit type of knowledge to a student. As this type of knowledge can't be delivered in a perfect form, the error caused on its method of delivery should be compensated via taking a spiral cycle of converting knowledge into different formats. Thus, a teacher (tutor) documents a concept (knowledge to be taught) and so converts that knowledge into a form of articulated explicit knowledge through an externalisation process. A content management system (CMS) whether to be used in the form of an online content provider or in a traditional face-to-face class delivers the articulated knowledge in the form of explicit knowledge through a combination process. Then it is the responsibility of the learner to gain and understand as much as s/he can via the process of internalisation to convert the explicit knowledge into tacit knowledge. As shown above, knowledge conversion must happen between individuals and not within each individual's mind in an isolated environment.

The main difference between teacher- and learner-centred systems is that each one interacts with the articulated knowledge differently. The process of determining this method of interaction could ease the process of defining the boundary of implicit and tacit knowledge.

Teacher-centred systems require face-to-face sessions for their method of delivery of knowledge; which in turn requires a socialisation process as a procedural method of sharing tacit knowledge. On the other hand, because tacit knowledge cannot be articulated, the amount of shared knowledge through different processes (teacher-centred in comparison to learner-centred systems) would create a completely different form of transferred knowledge. Basically, from a knowledge transferring system's point of view:

$$
\text { Traditional Teacher }- \text { center Systems } \neq \text { Learner }- \text { centred Systems }
$$

As a starting point, two questions could be asked here and they are: i) How closer a learnercentred environment can get to a teacher-centred environment? and ii) is there any involvement of personality of teacher and learner with the knowledge-transferring environment? Answering these two questions require further study on different types of knowledge and their relevancy together.

Following the discussion above (Types of knowledge), teaching environment (medium) is a more controllable environment than a learning environment (from a teacher's point of view), because the interaction between a teacher and a learner involves different variables, such as reading student's body language (e.g. is the teaching material exciting or boring?) and the mood of both parties involved in the class are considered factors in the medium of knowledgetransfer. Moreover, in a learner-centred learning environment (from learner's point of view), the learner is on control and hence the procedure which has been put in place by an instructional designer should be well designed and sufficiently comprehensible to give proper direction to the learner for his/her learning activities) [24]. Despite the fact that content materials between both teacher- and learner-centred methods could be the same, in the hope of an equivalent outcome, because of the presence of tacit knowledge in teaching materials,
Personalizing of e-learning systems 
the outcome of both methods for the purpose of delivery of knowledge will never be the same (as knowledge in the form of tacit cannot be articulated), thus:

$$
\text { Outcome of learner - centred methods } \neq \text { Outcome of Teacher }- \text { centred methods }
$$

However, the knowledge management system can support a teaching and/or learning environment and so to be used as a learning system [25-27]. This support is in the form of transferring knowledge. ${ }^{1}$

Given different types of strategic knowledge management and learning styles we develop the following hypothesis:

H1: Combination of learning styles and selection of a specific strategic knowledge are key differentiators on the selection of types of e-learning systems.

H2: Accurately selected type of e-learning system designed based on strategic knowledge and the learner's learning style can indicate an increase in learning performance.

\section{Experimental design}

In order to devise a set of business rules for either teacher- or learner-centred environments it is necessary to determine those components and the boundary around them which is known as identifying the scope of this study: i) the knowledge creator, ii) knowledge transferring environment (medium), and iii) the recipients of that knowledge. As such, those steps would initiate the design and development phases of a semi-tacit-based knowledge management system. On the other hand, by further studying shared values and identifying differences between processes of personalisation of teacher- and learner-centred environments, this approach would provide evidence in areas which could be articulated, specifically based on the philosophy of the learner-centred environment and not the teacher-centred one. The study of identified and articulated knowledge would then formulate the understanding of key factors involved in defining the boundary of the area of implicit knowledge, which in turn would support this study in finding relations between individual's thinking and decisionmaking methods (processes) with the existing knowledge in hand (in the form of tacit knowledge). In another word, different individuals are having different learning styles, which would be a determinant factor in defining those set of business rules in learning management systems which will be investigated and defined later on.

Figure 3 presents a basic idea behind the form of converting the tacit into implicit knowledge so to have a form of a usable knowledge on a topic. As such the principles of drawing those functions (conversion of tacit into implicit knowledge) should be based on the individual's learning style. This is the core reasoning behind the design and development of any Personalisation of ELSs.

\section{Development of a solution}

Learning and understanding the relationship between an individual's learning style (which is mainly structured on the bases of an individual's decision-making process) and strategic knowledge require further clarification on the concept of learning styles. As a learning style would determine one's approach towards interacting with an environment for the purpose of either gaining knowledge or doing a task, this concept would indicate the following relationship as shown in Figure 4.

Figure 4 proposes an illustration of the process of converting declarative into procedural knowledge in the form of tacit knowledge. It clearly shows the process of personalisation of strategic knowledge creation, updating the Nickols framework [15] for the procedural 


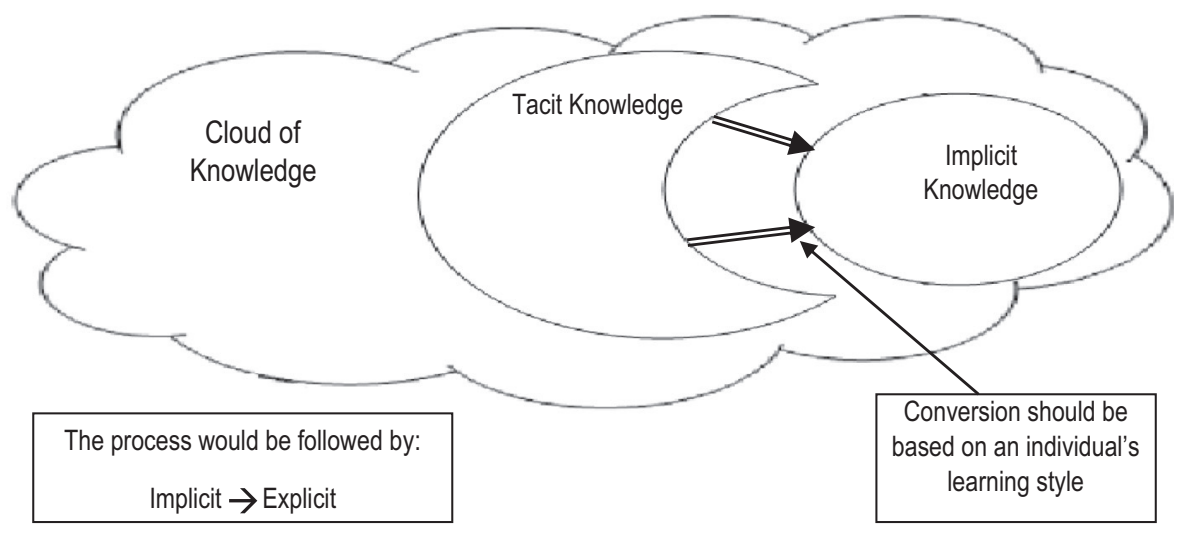

Personalizing

of e-learning

systems

159

Figure 3.

Categorisation of knowledge and a

diagram on the conversion of tacit to implicit knowledge.

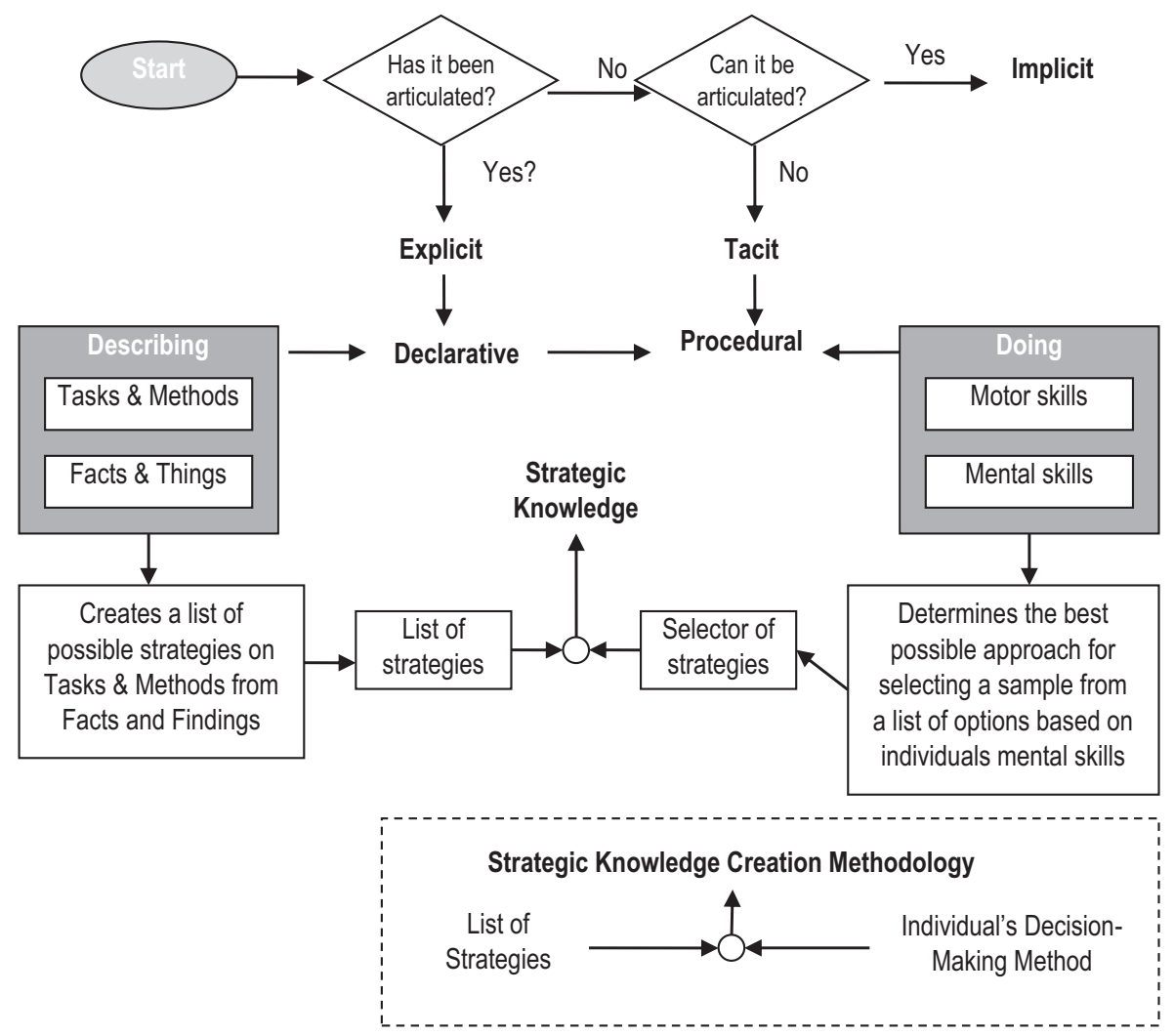

Individual's learning style depends on his/her decision-making method and it is unique to his/her understanding of the problem.

Figure 4. Illustration of the process of personalisation of strategic knowledge creation; updating the Nickols [15] framework on types of knowledge. 
$\mathrm{ACI}$

17,1

160

approach on the involvement of an individual's decision-making method for selecting a strategy. Furthermore, the process could be reversed if the purpose of conversion is to create implicit knowledge out of tacit knowledge, so as to define the boundary of this conversion. This conversion takes into account that tacit knowledge cannot be articulated. As it is mentioned above, the personalised strategic knowledge draws a framework for the creation and selection of strategies which are based on individual's decision-making style when it comes to dealing with learning new subject (gaining new knowledge), or in another word the strategic approach to the selection of a specific strategy is based on individual's learning style.

Decisions on "how to describe knowledge on a topic", "when to describe it", and "finding reasons on methods of describing those facts" depend on an individual's decision-making style. In that view the strategic knowledge would be a determinant factor in clarifying the relationship between Learning Style, Strategic Knowledge (SK) and Knowledge Transferring (KT):

- KT is the reason for the need of an ELS.

- LS is the determinant factor for selecting SK

- SK is about "know-when" and "Know-why" under the category of "know-about"

Figure 5 illustrates the relationship between all three main factors involved in defining the personalisation of e-learning systems.

Details of how relationships between objects in Figure 5 are related have been described in Figure 6 and Figure 7 in more detail.

Figure 5.

Illustrating the relationship between Knowledge Transferring (KT), Strategic Knowledge (SK) and individual's Learning Style (LS).

\section{Figure 6.}

High-level view of the process of creating Procedural Knowledge (PK) from Declarative Knowledge (DK) - 1 .

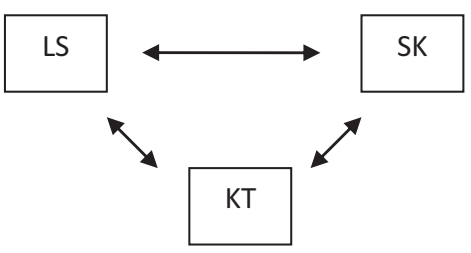

Figure 7.

Detailed view of the process of creating Procedural Knowledge (PK) from Declarative Knowledge (DK) -2 .
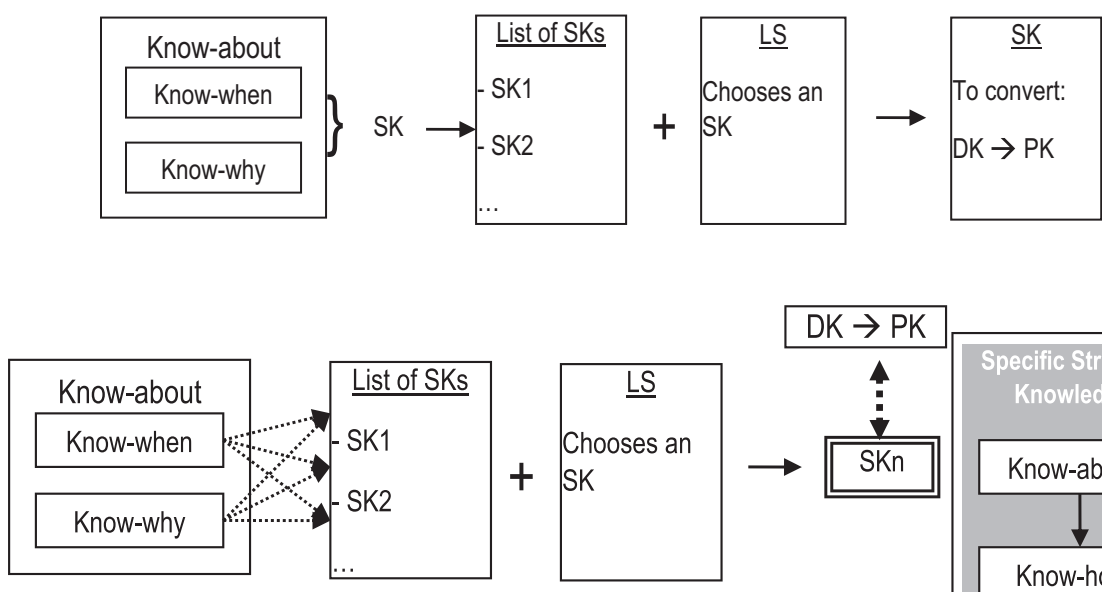
SK creates a list of options on "know-about" then LS is the factor for selecting the specific SK, which would be the determining factor on continuing (or moving) from declarative knowledge to procedural knowledge.

Thus:

The product of Figure 6 and Figure 7 (moving contents from the form of the declarative knowledge to procedural knowledge) is non-articulated knowledge, which is based on individual's decision-making style [31], a collection of productions known as Procedural Knowledge. As such, a series of IF-THEN statements are being presented and then individuals make a selection based on their understanding of the situation in order to make a choice. This newly configured knowledge is a combination of tacit knowledge with its converted form to existing explicit and/or implicit type of knowledge. On the other hand, declarative knowledge needs an additional piece of knowledge in order to become procedural knowledge (in the form of additional tacit knowledge and so must be converted into explicit knowledge).

Thus:

$$
\mathrm{DK}+[\text { something }] \rightarrow \mathrm{PK}
$$

Or

"Declarative Knowledge" with the addition of "Something" would become "Procedural Knowledge"

By elaborating further to know more on that [something] it could be said that, when we see something we start to describe and simulate it to a similar shape or concept from the archives in our memory, similar to Polanyi's example of picking someone's face out of a crowd, which is the bases of today's artificial intelligence for face recognition which has been designed based on deep learning algorithms [32,33]. But the process (in itself know-how) of giving a description or creating a simulation in the memory is tacit knowledge, which can't be articulated. Despite the fact that there are approaches to finding some implicit knowledge from the process, it should be noted that two people's approach to obtaining strategic knowledge cannot be the same, as it is tacit knowledge and based on their method of knowhow the product of knowledge conversion from declarative to procedural format are not the same [34]. Or in another word, an individual's unique decision-making method which is the key to an individual's unique learning style is a determining factor in approaching a knowledge concept. This individually based unique method establishes a set of roles and guidance when it comes to approaching and directing those concepts. The interaction with those concepts will be guided by a set of roles which are unique to the learner's learning style.

Thus: $\mathrm{LS} \propto \mathrm{SK} \propto \mathrm{KT}$

"Learning Styles" relates to "Strategic Knowledge" which in turn relates to "Knowledge Transferring".

\section{Findings}

This section provides the outcome of investigation and indication on proofs of both hypotheses mentioned earlier in Section 1.

On the relevancy of types of ELSs and learning styles with the effects of strategic knowledge, it has been found that the strategic knowledge (SK) has a clear impact on any knowledge transferring system (KT) that is affected by an individual's learning style (LS). These personal characteristics from individuals' learning style are determined on the base of a personal decision-making process which is unique to each person. This analysis determines the main difference between teacher- and learner-centred learning systems.

In the light of this argument and understanding the relationship between the effect of tacit knowledge presented in teaching and learning environments, following types of ELSs can be concluded:
Personalizing of e-learning systems 


\section{$\mathrm{ACI}$}

17,1

\section{2}

a. Teacher-centred learning environment (pedagogical views)

An environment where a teacher (instructional designer) navigates through utilising tacit knowledge to deliver the required teaching materials in the form of either explicit and/or implicit knowledge.

b. Learner-centred learning environment (andragogical views)

An environment where an instructional designer acquires the best possible method for the delivery of knowledge to work with existing teaching materials in the form of explicit and implicit knowledge; and then it would be the responsibility of the learner to gain as much knowledge as possible as s/he can by navigating through the structured knowledge.

c. Personalised learning environment (Andragogical and Heutagogical views)

An environment which includes an individual's decision-making method in the form of a learning style through strategic knowledge in a learning environment.

d. Personalised e-learning system (PELS)

PELS is an environment where the process of finding an individual's learning style would be done through an electronically developed system and as such the learner should continue to use the system to gain the required knowledge electronically.

e. Adaptable and/or adaptive e-learning systems (AVALELS)

Depending on how an ELS controls the delivery of learning materials these type of ELSs can be divided into two types of e-learning systems. If a learner defines a set of preferences before starting to interact with the ELS, then this is called an adaptable ELS (A LELS); and if the ELS itself be on control and continuously supervise the delivery of the learning materials to a learner, with no prior interaction from the learner, this is called an adaptive e-learning system ( $\mathrm{A}_{V} \mathrm{ELS}$ )

In supporting the second hypotheses (H2) a quantitative experiment was designed which has been presented in [35,36]. Findings from that experiment (Table 1) indicate on the use of strategically crafted content of learning objects to show the efficiency of 'competency' type of assessment questions in adaptable e-learning system - $A_{L} E L S$ (with the indication of

\begin{tabular}{|c|c|c|c|c|}
\hline $\begin{array}{l}\text { Type of } \\
\text { Assessment } \\
\text { Questions }\end{array}$ & \multicolumn{2}{|c|}{$\begin{array}{l}\text { Type of E-learning } \\
\text { System and its relevant } \\
\text { correlation coefficient }\end{array}$} & $\begin{array}{l}\text { Percentage of } \\
\text { performance } \\
\quad \text { in } \%\end{array}$ & Comment \\
\hline Recall & 0.860 & 0.904 & $4.88 \%$ & $\begin{array}{l}\text { Indications of } 4.88 \% \text { better } \\
\text { performance achieved by a recall type } \\
\text { of assessment question with a } \\
\text { personalised type of ELS }\end{array}$ \\
\hline Competency & 0.826 & 0.781 & $5.43 \%$ & $\begin{array}{l}\text { Indications of } 5.43 \% \text { better } \\
\text { performance achieved by a competency } \\
\text { type of assessment question with an } \\
\text { adaptable type of ELS }\end{array}$ \\
\hline Understanding & 0.842 & 0.885 & $4.89 \%$ & $\begin{array}{l}\text { Indications of } 4.89 \% \text { better } \\
\text { performance achieved by an } \\
\text { understanding type of assessment } \\
\text { question with a personalised type of } \\
\text { ELS }\end{array}$ \\
\hline
\end{tabular}

Table 1 .
Comparison between types of assessment questions and their use in different ELSs. 
$5.4 \%$ - or with correlation coefficient of 0.826 compared to 0.781 to be precise), with 'recall' and 'understanding' types of assessment questions, with indication of $4.88 \%$ for recalling type of assessment questions (0.904 in comparison to 0.860 of PELS) and $4.89 \%$ for understanding type of learnt materials (0.885 in comparison to 0.842 of PELS).

This indicative outcome clearly shows the relevancy and dependability of learner's learning preferences and the type of e-learning system in which a learner uses for the delivery of knowledge in the context of the strategic learning environment.
Personalizing of e-learning systems

\section{Discussion}

Through this article, the author has attempted to present a new understanding of the relationship between an individual's learning style, strategic knowledge and transferring knowledge. By further exploration of concepts of knowledge, knowledge management, needs for knowledge management systems, different types of knowledge, converting knowledge into different forms, and knowledge transferring systems our understandings on learning style-based learning management systems can be improved.

Knowledge transferring mechanisms (machine) acquire learning systems for its purpose. As mentioned earlier (in section 1), knowledge in itself does not make any sense and it has to be delivered to another source so to be stored, processed and then able to produce new outcome; learning systems have been used for this purpose. Learning systems (as attempted solutions towards transferring tacit knowledge with the support of explicit knowledge through externalisation, combination and internalisation processes) imitate a form of a knowledge transferring machine. This approach has been used in the research because it is not possible to use any kind of machine as a means for the delivery of knowledge in the medium of the socialisation process of the knowledge conversion without error in its transference; although, there have been few attempts made in this regard on transferring the tacit knowledge with the support of Information Systems such as online collaborative environments and many other social network service types of websites [37-40]. All kinds of social networking service sites attempt to present information on individuals' self-sensing and self-expressing identities which is fundamental to the ecology of tacit knowledge [41,42].

There are advantages to the designing and development of a learning environment especially with the help of technology. As this is one of the main objectives of this research that supports the control of a learning environment and updates its teaching materials; especially on the process of its production. It is unlike a traditional paper-based teaching environment which would require a tremendous amount of work to update its content materials. Besides, with the support of technology, managing the profile of a learner's learning style and relating it to his/her required learning materials is much easier in comparison to the use of traditional teaching classes, which is almost impossible to do so.

Through the evaluation of shared points of views between concepts of (i) an individual's unique decision-making process (method) and (ii) individual's unique learning style, it could be argued that a unique approach of the method of articulating knowledge would support the design and development of a unified form of a knowledge-based system. The best form of this type of system is known as personalised e-learning system. This confirms the compatibility of this outcome based on an individual's understanding of the accessible knowledge in the form of converting tacit knowledge into an implicit and then to explicit types of knowledge. In addition to the above discussion, a learning system (which provides contents in the form of sources of knowledge accessible to the learner), and learner's unique learning style would support an educational mechanism known as "personalised learning system." This type of system leads to the design and development of a personalised e-learning system. 
$\mathrm{KT}_{\mathrm{TK}} \equiv \mathrm{KT}_{\text {Learing Systems }}+\mathrm{LS}+e$

17,1

where

$\mathrm{KT}_{\mathrm{TK}}$ stands for transferring knowledge of type tacit

$\mathrm{KT}_{\text {Learning Systems }}$ stands for learning systems type of knowledge transferring

LS stands for learning styles

$e$ stands for dissipation error or the amount of knowledge which is transformed into other types of messages while senders (instructors) attempts to convert tacit knowledge into explicit knowledge (externalisation process) and learners attempt to convert the explicit knowledge into a newly formed and constructed tacit knowledge (internalisation process).

Knowledge transferring of tacit knowledge is a combined process of knowledge transferring systems and an individual's learning style; or basically, to transfer tacit knowledge, a learning system would be required with the consideration of a learner's learning style, known as a personalised learning system.

$$
\mathrm{ELS}+\mathrm{LS} \equiv \text { Personalised ELS }
$$

Above relation is another indication on the relevancy of personalised e-learning systems with individual's learning styles based on strategic knowledge. Meanwhile, the perspective of knowledge transferring systems requires further exploration of learning philosophies including their approaches on different interpretations of teacher-learner interaction. Such as, how the electronically-based learning environment is capable of increasing efficiency of transmission of tacit knowledge into an explicit form of knowledge; mainly because a computerised environment is capable of making strategic decisions based on learner's learning style, which was traditionally not feasible by using pen and paper for a large cohort of students.

\section{Conclusions}

In this paper a novel approach is being recommended on understanding strategic knowledge and the role of learner's learning preferences on the delivery of knowledge. Those two elements are keys to personalisation of e-learning systems, and as such an effective method on the delivery of tacit knowledge with the use of externalisation $\rightarrow$ combination $\rightarrow$ internalisation path to replace the socialisation method (tacit knowledge), which is the core principle on the design and development of e-learning systems.

Furthermore, through the quantitative findings, by providing empirical evidence on differentiating between adaptable and personalised e-learning systems it is shown how taking the route of delivery of tacit knowledge as opposed to socialization creates a series of environments to support pedagogical, andragogical and heutagogical methods for delivery of knowledge and as such different learning environment; like adaptable, adaptive and personalised e-learning systems. These designs might function as roadmaps for instructional designers in order to make a sound judgement pertinent to the selection of e-learning systems that incorporates the underlining learning style efficiently.

Based on the current work the future research can extend the investigation on understanding learning styles and its impact on strategic knowledge in order to investigate a new horizon on adaptive and adaptable e-learning systems. This will create additional learning environments in which the effectiveness of different learning methods can be measured. 
Note

1 For new publications on e-learning systems and knowledge management the interested reader is referred to [28-30].
Personalizing

of e-learning systems

\section{References}

[1] I. Torres, M. Guerreiro, P. Rodrigues, A. Monarca, D. Barradas, Creation of a tacit knowledge scale in succession process of family business, in: 14 International Conference on Intellectual Capital, Knowledge Management \& Organisational Learning, Hong Kong Polytechnic University, Hong Kong, China, 2017, pp. 277-283, 7p. Accessed on July, 12, 2018. [Online]. http://web.a. ebscohost.com/ehost/pdfviewer/pdfviewer?vid=0\&sid=2028a813-02f4-4cec-9f589a37259159e4\%40sessionmgr4006.

[2] I. Nonaka, The Knowledge-Creating Company. Harvard Business Review, Reprint, 2008.

[3] I. Nonaka, H. Takeuchi, The Knowledge-creating Company - How Japanese Companies Create the Dynamics of Innovation, Oxford University Press, New York/Oxford, 1995, p. 62.

[4] A. Haberberg, A. Rieple, A Strategic Management, Theory and Application, Oxford University Press, 2008, pp. 408-409.

[5] Knowledge, Merriam-Webster Online Dictionary. Accessed on 6 June 2018. [Online]. http://www. merriam-webster.com/dictionary/knowledge, 2018.

[6] R. Chugh, Do Australian Universities encourage tacit knowledge transfer? in: Proc. KMIS 2015, 7th International Joint Conference on Knowledge Discovery, Knowledge Engineering and Knowledge Management, Lisbon, Portugal, 2015, pp 128-135. Accessed on: Jun, 6, 2018, [Online]. doi: 10.5220/0005585901280135.

[7] M. Jennex, Big Data, The Internet of Things, and the Revised Knowledge Pyramid, November 2017ACM SIGMIS Database 48(4):69-79 Accessed on: Jun, 6, 2018, [Online]. DOI: 10.1145/3158421. 3158427.

[8] K. Laudon, J. Laudon, Management Information Systems, Managing The Digital Firm, 14th ed., Pearson-Prentice Hall, 2015, pp. 434.

[9] J. O'Brien, G. Marakas, Management Information Systems, 10th ed., McGrawill/ Irwin, 2013, pp. 62.

[10] M. Polanyi, Tacit knowing: its bearing on some problems of philosophy, Rev. Modern Phys. 34 (4) (1962) 601-616, Accessed on: Jun, 6, 2018, [Online]. Available: https://journals.aps.org/rmp/ abstract/10.1103/RevModPhys.34.601.

[11] M. Polanyi, The Tacit Dimension, Reissue ed., University of Chicago Press, 2009.

[12] R. Nelson, S. Winter, An Evolutionary Theory of Economic Change, Belknap Press of Harvard University Press, Mass. US, 1982.

[13] P. Baumard, Tacit knowledge in organizations, Sage London, Thousand Oaks, New Delhi, 1999.

[14] R. Grant, Contemporary Strategy Analysis, sixth ed., Blackwell Publishing, 2008, pp. 159-165.

[15] F. Nickols, The knowledge in knowledge management, in: J.W. Cortada, J.A. Woods, (Eds), The Knowledge Management Yearbook 2000-2001, pp. 12-21, Boston, MA: Butterworth-Heinemann. Accessed on: Jun, 6, 2018, [Online]. Available: http://www.nickols.us/Knowledge_in_KM.htm.

[16] I. Nonaka, K. Umemoto, D. Senoo, From information processing to knowledge creation: a paradigm shift in business management, Technol. Soc. 18 (2) (1996) 203-218.

[17] S. Tseng, The effects of information technology on knowledge management systems, Expert Syst. Appl. 35 (2008) 150-160.

[18] S. Nätti, P. Ulkuniemi, Saara Pekkarinen, Implementing Modularization in Professional Services-The Influence of Varied Knowledge Environments, Knowledge and Process 
Management, Vol. 24, No. 2 pp 125-138, 2017. Accessed on: July, 12, 2018, [Online]. Available: (www.wileyonlinelibrary.com) DOI: 10.1002/kpm.1538.

[19] I. Nonaka, On a knowledge creating organisation. Mimeo, paper presented at the Associazione Nazionale Formatori, Parma, October, 23rd-30th, 1993.

[20] C.W. Choo, The Knowing Organisation, Oxford University Press, 1998.

[21] F.M. Alkhaldi, M. Olaimat, Knowledge conversion and transfer: a mathematical interpretation, Interdisciplinary J. Inf. Knowledge Manage., 1, 137-149, 2006. Accessed on Jun, 7, 2018. [Online]. Available: http://ijikm.org/Volume1/IJIKMv1p137-149Alkhaldi.pdf.

[22] Q. Wu, Y. Sang, S. Zhang, Y. Huang, Danmaku vs. forum comments: understanding user participation and knowledge sharing in online videos, in: GROUP 18, Proc. 2018 ACM Conference on Supporting Groupwork, pp. 209- 218. Jan, 7-10, 2018, Sanibel Island, FL, USA. Accessed on Jun, 7, 2018. [Online]. Available: https://doi.org/10.1145/3148330.3148344.

[23] J. Meehan, Knowledge management: a case of quelling rebellion? In: Critical Management Studies Conference, UMIST July 1999, Manchester, UK. Accessed on Jun, 7, 2018. [Online]. Available: http://www.mngt.waikato.ac.nz/ejrot/cmsconference/1999/documents/Information\%20Knowledge /gilson.pdf, 1999.

[24] B. Saleena, S.K. Srivastsa, Using concept similarity in cross ontology for adaptive e-Learning systems, J. King Saud Univ. - Computer Inf. Sci., 27, 1-12, 2015. Accessed on Jun, 7, 2018. [Online]. Available: https://doi.org/10.1016/j. jksuci.2014.03.007.

[25] M. Alavi, D.E. Leidner, Review: Knowledge Management and knowledge management systems: Conceptual foundations and research issue, MIS Quarterly, vol. 25, 1, pp. 107-136, Mar, 2001. Accessed on Jun, 7, 2018. [Online]. Available: http://www.jstor.org/stable/3250961.

[26] M. Raman, T. Ryan, L. Olfman, Designing knowledge management systems for teaching and learning with wiki technology, J. Inf. Systems Educ., vol. 16(3), 311-320, Fall 2005. Accessed on Jun, 7, 2018. [Online]. Available: http://fantasticfour.pbworks.com/f/designing_km_teaching_ wiki.pdf.

[27] T.A. Hurley, C.W. Green, Knowledge management and the nonprofit industry: a within and between approach, J. Knowledge Manage. Practice, January 2005. Accessed on Jun, 7, 2018. [Online]. Available: http://www.tlainc.com/articl79.htm.

[28] K. Munir, M.S. Anjum, The use of ontologies for effective knowledge modelling and information retrieval, Appl. Comput. Informatics, 14(2), 116-126, July 2018. Accessed on July, 15, 2018. [Online]. Available: https://doi.org/10.1016/j.aci.2017.07.003.

[29] M. Anshari, M.N. Almunawar, S.A. Lim, A. Al-Mudimigh, Customer relationship management and big data enabled: personalization \& customization of services, Appl. Comput. Informatics, Furth coming, May 2018. Accessed on July, 16, 2018. [Online]. Available: https://doi.org/10.1016/j. aci.2018.05.004

[30] S. Bekhti, N. Matta, C. Djaiz, Knowledge representation for an efficient re-use of project memory, Appl. Comput. Informatics, 9(2), 119-135, July 2011. Accessed on July, 13, 2018. [Online]. Available: https://doi.org/10.1016/j. aci.2011.05.004.

[31] J.R. Anderson, Acquisition of cognitive skill, Psychol. Rev., 89 (4), 369-406, 1982. Accessed on Jun, 7, 2018. [Online]. Available: http://dx.doi.org/10.1037/0033-295X.89.4.369.

[32] W. Sun, H. Zhao, A complementary facial representation extracting method based on deep learning, Neurocomputing. Sep2018, 306, 246-259. 14p. Accessed on July, 12, 2018. [Online]. Available: https://www.researchgate.net/publication/325001439_A_Complementary_Facial_Repr esentation_Extracting_Method_based_on_Deep_Learning.

[33] M.A. Aljanabi, Z.M. Hussain, S.F. Lu, An Entropy-Histogram Approach for Image Similarity and Face Recognition, Math. Problems Eng., Sep2018, 2018, 1-18. Accessed on July, 12, 2018. [Online]. Available: https://www.hindawi.com/journals/mpe/2018/9801308/. 
[34] K. Matzler, B. Renzl, J. Müller, S. Herting, T.A. Mooradiand, Personality traits and knowledge sharing, J. Econ. Psychol., 29, 301-313, 2008. Accessed on Jun, 7, 2018. [Online]. Available: https:// doi.org/10.1016/j.joep.2007.06.004.

[35] A. Mustafa, Impact of learner control on learning in adaptable and personalised e-learning environments, PhD Thesis. School of Comp. and Math. Sci., University of Greenwich, London, UK, 2011. Accessed on Jun, 7, 2018. [Online]. Available: http://gala.gre.ac.uk/7143/.

[36] A. Mustafa, Effects of types of assessment questions on learning performance of two types of elearning systems, adaptable and personalised ELSs, in: International Engineering, Science and Education Conference, INESEC 2016, Diyarbakir, Turkey, 01-03 December 2016. Accessed on Jun, 7, 2018. [Online]. Available: http://inesec2016.ineseg.org/proceedingbooks/EducationProceeding_ Book.pdf \#page $=9$.

[37] Facebook, Social Network Service, 2004. Accessed on Jun, 7, 2018. [Online]. Available: http://www. facebook.com.

[38] MySpace, A Social Network Service, 2004. Accessed on Jun, 7, 2018. [Online]. Available: https:// myspace.com.

[39] Hi5, Social Network Service, 2004, Accessed on Jun, 7, 2018. [Online]. Available: http://www. hi5.com.

[40] Twitter, Social Network Service, 2006, Accessed on Jun, 7, 2018. [Online]. Available: http://www. twitter.com.

[41] J. Ginger, The Facebook Project: Fostering Multidisciplinary e-Social Science, LIS590: Distributed Knowledge, Bruce \& Haythornthwaite, Revision 1, Oct, 3, 2008. Accessed on Jun, 7, 2018. [Online]. Available: http://www.thefacebookproject.com/research/jeff/publications/esocialscience.html.

[42] H. Taghvaei, Tacit Knowledge and Deep Ecology: A Hermeneutic Approach to the Concept of Tacit Environmental Knowledge in Landscape Architecture, Environmental Sciences, vol. 6, No.1, pp. 111-122, Autumn 2008. Accessed on Jun, 7, 2018. [Online]. Available: https://www.academia. edu/4061701/Tacit_Knowledge_and_Deep_Ecology_A_Hermeneutic_Approach_to_the_Concept_ of_Environmental_Tacit_Knowledge_in_Landscape_Architecture.

\section{Corresponding author}

Alan Mustafa can be contacted at: alan.mustafa@auk.edu.krd
Personalizing of e-learning systems

For instructions on how to order reprints of this article, please visit our website:

www.emeraldgrouppublishing.com/licensing/reprints.htm

Or contact us for further details: permissions@emeraldinsight.com 